\title{
Dev Serebral Hidatik Kist Olgusu
}

\author{
A Giant Cerebral Hydatid Cyst
}

Serap Teber ${ }^{1}$, Sultan Ay², Aydan Değerliyurt ${ }^{2}$

' AÜTF Çocuk Sağlığı ve Hastalıkları Çocuk Nörolojisi Bilim Dalı 'Ankara Cocuk Sağlığı ve Hastalıkları Hematoloji Onkoloji Eğitim Arastirma Hastanesi
Geliș tarihi : 28.03.2014 • Kabul tarihi: 28.04.2014

\section{İletișim}

Doç. Dr. SerapTEBER

Tel: 03125956404

Faks: 03123191440

E-posta: seraptteber@gmail.com

Ankara Üniversitesi Tıp Fakültesi Cocuk Sağlığı ve Hastalıkla AD. Çocuk Nörolojisi BD. 06510 Cebeci/ ANKARA TURKEY

Kist hidatik, Echinococcus granulosus'un neden olduğu paraziter bir enfestasyondur. Hidatik kist hastaların \%75 inde karaciğeri, \%15 inde akciğeri tutar. Diğer organ tutulumları \%10 oranında görülür. Santral sinir sistemi tutulumu ise \%1 oranında görülür ve bu vakaların çoğu çocukluk çağında tespit edilmiștir. Kistler 5-20 yıl gibi bir sürede yavaș büyür ve genelde $5 \mathrm{~cm}$ çapa ulașıncaya kadar belirti vermezler. Boyut büyüdükçe basınç ve tıkayıcı etkilere bağlı olarak klinik bulgular gelișir. Biz burada karaciğer kist hidatiği nedeniyle izlenmesine rağmen nörolojik bulguları gözden kaçan ve dev boyutlara ulașan bir kist hidatik olgusunu sunmayı amaçladık.

\section{Anahtar Sözcükler: Hidatik Kist, Serebral}

Hydatid cyst is a parasitic infection caused by Echinococcus granulosus. Hydatid cyst involves liver, in $75 \%$ of cases and lungs, in $15 \%$ of cases. Other organ involvement is seen in $10 \%$ of cases. Central nervous system involvement is seen only in 1\% of cases and most of these cases are children. The cysts grow slowly in 5-20 years and generally don't give symptom until they become $5 \mathrm{~cm}$ in diameter. As the size becomes larger the symptoms associated with increased pressure and obstructive effect develop. Herein we report a patient with hydatid cyst whose neurologic symptoms missed although the huge size of the cyst.

Key Words: Hydatid Cyst, Cerebral

Kist hidatik, Echinococcus granulosus'un neden olduğu paraziter bir enfestasyondur. Hastalık insana fekal oral olarak rastlantısal olarak bulaşmakta ve kan yoluyla değişik organlara ulaşarak yerleşip değişik klinik tablolara neden olmaktadır(1).

Hidatik kist hastaların $\% 75$ inde karaciğeri, \%15 inde akciğeri tutar. Diğer organ tutulumlar1 \%10 oranında görülür (2,3). Santral sinir sistemi tutulumu ise $\% 1$ oranında görülür ve bu vakaların çoğu çocukluk çağında tespit edilmiştir. Santral sinir sisteminde herhangi bir alanda görülebilir, sıklıkla her iki serebral hemisferde orta serebral arterin beslediği parietal ve bunu takiben frontal lobta görülür $(3,4)$.

Semptomlar; hidatik kistin, santral sinir sistemindeki lokalizasyonuna ve kitle etkisine bağlı olarak gelişen kafa içi basınç artışı sendromu (KİBAS) ve buna ikincil olarak kranial sinir paralizileri şeklindedir $(5,6)$. Kistler 520 yll gibi bir sürede yavaş büyür ve genelde $5 \mathrm{~cm}$ çapa ulaşıncaya kadar belirti vermezler. Boyut büyüdükçe basınç ve tıkayıcı etkilere bağlı olarak klinik bulgular gelişir $(7,8)$.

Biz burada karaciğer kist hidatiği nedeniyle izlenmesine rağmen nörolojik bulguları gözden kaçan ve dev boyutlara ulaşan bir kist hidatik olgusunu sunmayı amaçladık.

\section{OLGU}

10 yaşında kız hasta, 4-5 aydır bașlayan ve giderek artan sol kol ve bacağını az kullanma sol ayağında içe doğru dönme ve 1-2 aydır şiddeti giderek artan baş ağrisı şikayeti ile geldi. Hastanın öyküsünden 1 ay önce karaciğer kist hidatiği nedeni ile girişimsel radyoloji teknikleriyle opere olduğu ve eş zamanlı albendazol tedavisi başlandığı öğrenildi. Hastanın Özgeçmişinden nörolojik gelişiminin yaşına uygun ilerlediği, ders başarısının iyi olduğu geçirilmiş önemli bir hastalığ öğrenildi, soy geçmişinde anne-baba 
akrabalığı olmadığı diğer kardeşlerinin sağ ve sağlıklı olduğu babasının kuzeninde spino serebellar ataksi olduğu öğrenildi. Hastanın yapılan fizik muayenesinde genel durumu iyi, sistemik muayenesi doğaldı. Hastanın geliş nörolojik muayenesinde; bilinç açı, koopere oryante, göz dibinde sağda daha belirgin olan bilateral papil stazı vard1, göz hareketleri serbestti. Işık refleksi direkt ve indirekt bilateral alınıyordu. Solda santral tipte fasiyel güçsüzlük vardı. Tonus sol kolda ve sol ayak bileğinde artmıştı. Derin tendon refleksleri bilateral canlı idi ve patolojik refleks yoktu. Serebeller testler becerikli, yürüyüş hafif sol hemiparetikti. Hastada primer karaciğer kist hidatik hastalığ1 öyküsü olması nedeni ile serebral hidatik kist, olabileceği düşünülerek kranial MRi çekildi. Hastanın çekilen MR'ı sağda paryetal bölgede 10x11 cm boyutlarında sola doğru şifte neden olan dev serebral kist hidatikle uyumlu bulundu (Şekil 1).

Hasta opere edildi. Kistin tamamı doğurtularak çıkartıldı. Patoloji raporu kist hidatik ile uyumlu kist eksizyonu şeklinde geldi. Ertesi gün çekilen kontrol kraniyal BT' de kistin çıarıldığı sağ paryetal alanda porensefalik kavite izlendi. Operasyon sonrasi albendazol tedavisine devam edildi. Hastanın kontrol muayenelerinde baş ağrısının gerilediği yürüme bozukluğunun ve spastisitenin gerilediği, hemiparezinin azalmakla birlikte devam ettiği görüldü. Hasta en son 1 y1l önce polikliniğe kontrole geldi; muayenesinde sol silik hemiparezi dışında bulgusu yoktu.

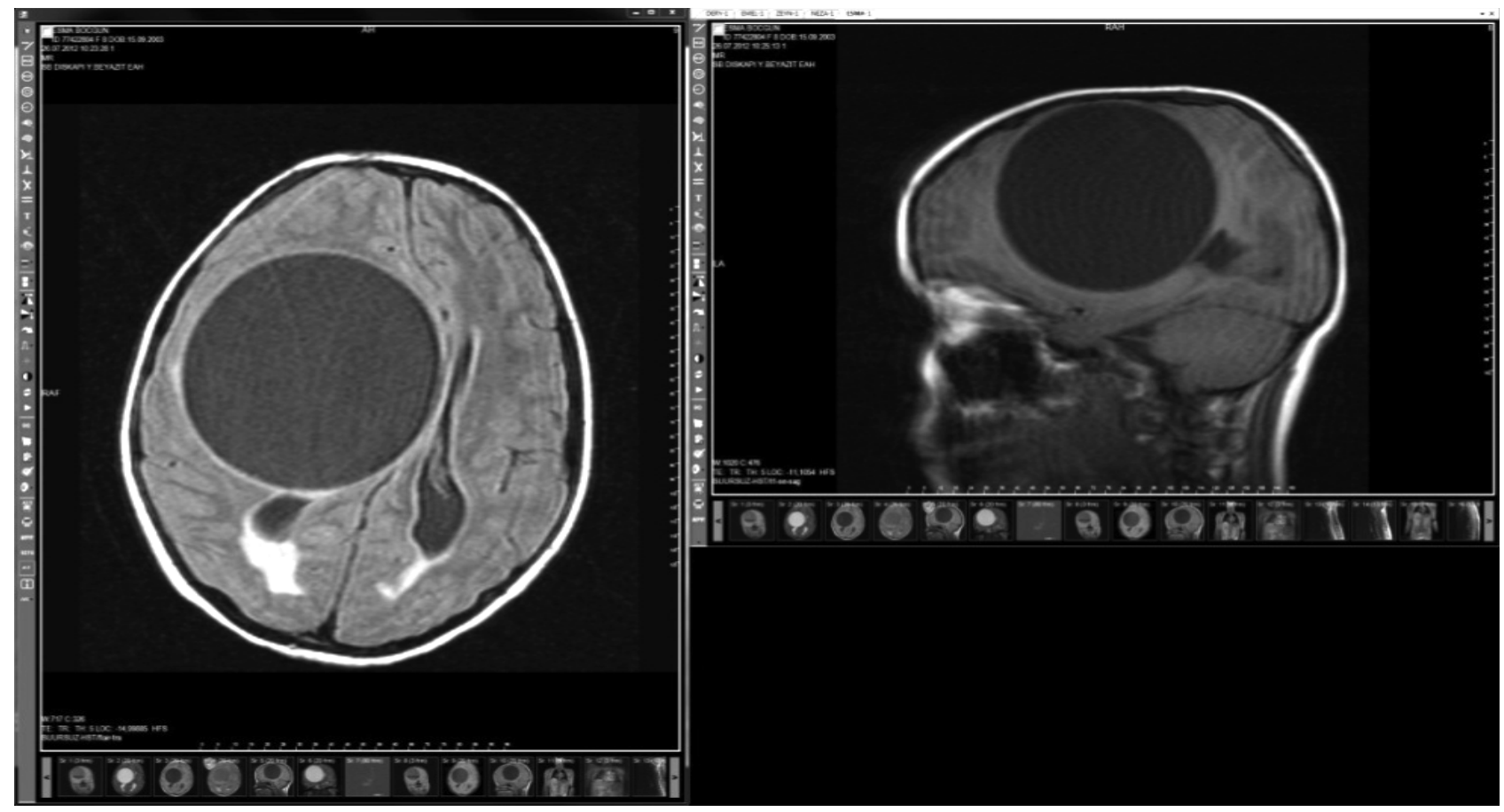

Şekil 1: Flair t2 aksiyel ve t1 sagital kesitlerde sağda paryetal alanda $10 \times 11 \mathrm{~cm}$ boyutlarında sola doğru şifte ve bilateral periventriküler oksipital horn çevresinde interstisyel ödeme neden olan dev hidatik kist.

\section{TARTIȘMA}

Kist hidatik kırsal yaşam ve hayvancıllı̆̆ın yaygin olduğu bölgelerde giderek artan paraziter bir hastalıktır. Bütün organlarda hastalık oluşturur fakat en s1k karaciğer ve akciğerde yerleşim gösterir (9). Serebral hidatik kist nadir görülmekte olup kist hidatik olgularının \%2-3'ünü oluşturur ve erişkine göre pediyatrik yaş grubunda daha s1k olarak (\%50-75) görülür. Klinik bulguları kistin sağlam olup olmamas1, yerleşimi, büyüklüğü ve organlara olan etkisi ile ilişkili olarak değişiklik göstermektedir. Büyümesi yavaş olduğundan semptomların gelişimi geç olmaktadır. Nörolojik bulgular genellikle intrakraniyal basinç artışına bağlı olarak gelişmektedir. Baş ağrısı ve kusma en sık görülen başlangıç semptomlarıdır. $\mathrm{Bu}$ şikâyetleri takiben, bizim hastamızda da olduğu gibi papil ödemi, hemiparezi, epileptik nöbetler, konuşma güçlüğü, kraniyal sinir felçleri ve ataksi görülebilmektedir $(10,11)$.

Tanı klinik ve laboratuvar bulguların birlikte değerlendirilmesi ile konulur. BBT ve MRG tek veya birlikte kist hidatik tanısını koymada oldukça başarılı ve preoperatif dönemde tedavi takibi açısından iyi bir yol göstericidir. Bizim olgumuzda olduğu gibi lezyonlar genellikle tektir. Çoğul lezyon oldukça nadirdir. Kistlerin en s1k görüldüğü yer yine olgumuzda görüldüğü şekliyle supratentoryal, orta serebral arterin sulama alanı olan parietal bölgedir. BBT ve MRG'da iyi sinırlı, ince duvarlı, sferik, homojen ve kistik lezyon şeklinde görülürler $(10,12,13)$.

Hidatik kist tedavisinde en etkili yöntem cerrahi olarak kistin çıarılmasıdır. 
Medikal tedavi cerrahi sonrasi nükslerin önlenmesi amaciyla cerrahi öncesi ve sonrasi verilmektedir (1). Duishanbai S. ve arkadaşlarının Çin'de 1985-2007 yıllar1 arasında takip ettiği 30 vakalık serebral kist hidatik olgularının 29'unda cerrahi ile kist tamamen çıkarılmış, 1 vaka ise ameliyat esnasinda kist rüptürüne bağlı ölümle sonuçlanmıştır (14). Bizim olgumuzda da cerrahi

\section{KAYNAKLAR}

1. Blanton R. Echinococcosis (E. Granulosus and E. multilocularis). Kliegman RM, Jenson HB, Behrman RE, Stanton BF, editors. Nelson Texbook of Pediatrics. Philedelphia: WB Saunders; 2007;1516-1519.

2. Pawłowski ZS, Eckert J, Vuitton DA, Amman RW, Kern P, Craig PS, et al. Echinococcosis in humans: clinical aspects, diagnosis and treatment. WHO/OIE Manual on Echinococcosis in Humans and Animals: a Public Health Problem of Global Concern 2001;20-68.

3. Pedrosa I, Saiz A, Arrazola J, Ferreiros J, Pedrosa CS. Hydatid disease: radiologic and pathologic features and complications. Radiographics 2000; 20: 795-817.

4. Turgut M. Intracranial hydatidosis in Turkey: its clinical presentation, diagnostic studies, surgical management, and outcome. A review of 276 cases. Neurosurg Rev 2001; 24: 200-208. operasyonla kist başarılı bir şekilde ç1karıldı ve 6 ay boyunca albendazol tedavisi verildi. Takiplerinde nüks görülmedi.

Bizim olgumuzda olduğu gibi karaciğer veya akciğer kist hidatiği olan çocuk hastalarda serebral tutulumun atlanmaması için, bu hastalar sık bir şekilde nörolojik muayene ile değerlendirilmeli ve şüphelenildiğinde

5. King CH. Echinococcosis. Mandell GL, Bennett JE, Dolin R, editors. Principles and Practice of Infectious Disease. New York: Churchill Livingston; 2000. p. 2962-2963.

6. Çakır D, Çelebi S, Gürpınar A, Ağın M, Bozdemir ŞE. Evaluation of cases with hydatid diseases. J Pediatr Inf 2009; 3: 104-108.

7. Altıntaş N, Tinar R, Çoker A, Echinococcosis (1. baskı) (Ed: Altıntaş N, Tinar R, Çoker A) Hidatoloji Derneği YayınNo:1, 2004;129-283.

8. Czermak BV, Akhan O, Hiemetzberger R, Zelger B, Vogel W et al, Echinococcosis of the liver. Abdominal Imaging, 2008;33: 133-143

9. Versaci A, Scuderi G, Rosato A, Ang1o LG, Oliva $G$ et al. Rare localisation of echinococcosis: personal experience. ANZ J Surg, 2005;75: 986-991 beyin MRG çekilmelidir. Hastalığın MRG bulguları tipik olduğundan ve bizim olgumuzda olduğu gibi cerrahi girişimde etkili bir şekilde uygulanabildiğinden hastaliğı̆n semptomları iyi takip edilmeli ve ölümcül olabilen bu hastalık için kür şansından yararlanılmalıdır.

10. Reddy R. Managing cerebral and cranial hydatid disease. Neurology India 2009; 57: 116-118.

11. Fenichel GM. Increased intracranial pressure. Fenichel GM, editor. Clinical Pediatric Neurology: A Signs and Symptoms Approach. Philadelphia: Elsevier Saunders; 2009; 93-117.

12. Bükte Y, Kemaloğlu S, Nazaroğlu H, Özkan U, Ceviz A, Şimșek M. Cerebral hydatid disease: CT and MR imaging findings. Swiss Med Wkly 2004; 134: 459467.

13. Sözüer EM, Akyüz M. Surgical therapy in hydatid disease. Turkiye Klinikleri J Gen Surg-Special Topics 2010; 3: 25-31.

14. Duishanbai S, Jiafu D, Guo H, Liu C, Liu B, Aishalong M, Mijiti M, Wen H.Intracranial hydatid cyst in children: report of 30 cases. Childs Nerv Syst. 2010; 26:821-827. 
